J. LIQ. CHROM. \& REL. TECHNOL., 25(1), 151-160 (2002)

\title{
DEVELOPMENT AND EVALUATION OF AN HPLC/DAD METHOD FOR THE ANALYSIS OF PHENOLIC COMPOUNDS FROM OLIVE FRUITS
}

\author{
Ana F. Vinha, ${ }^{1}$ Branca M. Silva, ${ }^{1}$ Paula B. Andrade, ${ }^{1}$ \\ Rosa M. Seabra, ${ }^{1, *}$ José A. Pereira, ${ }^{2}$ and M. Beatriz \\ Oliveira $^{3}$ \\ CEQUP, 'Serviço de Farmacognosia and ${ }^{3}$ Serviço de \\ Bromatologia, Faculdade de Farmácia, Universidade do \\ Porto, R. Aníbal Cunha, 164, 4050-047 Porto, Portugal \\ ${ }^{2}$ Escola Superior Agrária, Instituto Politécnico de \\ Bragança, Quinta de Sta. Apolónia, Apartado 172, 5300 \\ Bragança, Portugal
}

\begin{abstract}
A new HPLC/DAD methodology for separating nine phenolic compounds is described. This methodology is applied to the definition of qualitative and quantitative profiles of three Portuguese olive fruit cultivars (Cobrançosa, Madural and Verdeal). Two different extraction methods were needed for the complete definition of their profiles, one of them including a Sep-pack C18 cleaning step.

The chromatographic separation was achieved using a Spherisorb ODS2 $(25.0 \times 0.46 \mathrm{~cm} ; 5 \mu \mathrm{m}$, particle size $)$ column.
\end{abstract}

*Corresponding author. E-mail: pandrade@ff.up.pt 
The solvent system used was a gradient of water-formic acid (19:1) and methanol, with a flow rate of $0.9 \mathrm{~mL} / \mathrm{min}$.

The detection limit values for phenolic compounds were between 0.04 and $4.32 \mu \mathrm{g} / \mathrm{mL}$ and the method was precise. As a general rule, the recovery values were high.

This technique can also be useful in the discrimination of Portuguese olive fruit cultivars.

\section{INTRODUCTION}

Polyphenolic compounds influence the sensorial properties of olive fruits and virgin olive oils and are important markers for studying fruit characteristics of different cultivars and for controlling oil production processes. $(1,2)$ This class of phenolic compounds are widespread in nature and have been successfully applied to quality control of plant foodstuffs, (3) namely of fruit derivatives. (4)

A few chromatographic methods have been used to study the phenolic compounds of olive fruit. (5-9) So, this paper reports the development of a new HPLC/DAD methodology to separate, identify, and quantify nine phenolic compounds usually described in olive fruit. For an accurate quantification of all phenolics identified, two different extraction methods were needed.

\section{EXPERIMENTAL}

\section{Olive Fruit Samples and Standards}

Olive fruit samples (Cobrançosa, Madural and Verdeal cultivars) were harvested in November, in Trás-os-Montes (Northeast of Portugal). The cores were removed, and the pulps were immediately stored at $-50^{\circ} \mathrm{C}$, and lyophilized. Each lyophilized pulp was powdered before extraction of phenolic compounds.

The standards were from Sigma (St. Louis, MO, USA) and from Extrasynthése (Genay, France). Methanol and n-hexane were obtained from Merck (Darmstadt, Germany). The water was treated in a Milli-Q water purification system (Millipore, Bedford, MA, USA).

\section{Solid-Phase Extraction (SPE) Columns}

SPE-columns with the non-polar sorbent ISOLUTE C18 (non end-capped) (NEC) $(50 \mu \mathrm{m}$ particle size, $60 \AA$ porosity; $10 \mathrm{~g}$ sorbent mass $/ 70 \mathrm{~mL}$ reservoir 
volume) were purchased from International Technology Ltd (Mid Glamorgan, UK).

\section{Extraction of Phenolic Compounds from Olive Fruits}

\section{Extraction via SPE Column}

Each olive fruit sample (ca. $1.5 \mathrm{~g}$ ) was thoroughly mixed with methanol until complete extraction of the phenolic compounds (negative reaction to $\mathrm{NaOH}$ $20 \%$ ). The methanolic extract was filtered, concentrated to dryness under reduced pressure $\left(40^{\circ} \mathrm{C}\right)$, and redissolved in acid water $(\mathrm{pH} 2$ with $\mathrm{HCl})(\approx 50 \mathrm{~mL})$. The aqueous solution was then passed through an Isolute C18 (NEC) column, previously conditioned with $60 \mathrm{~mL}$ of methanol and $140 \mathrm{~mL}$ of acid water $(\mathrm{pH} 2$ with $\mathrm{HCl}$ ). The loaded cartridge was washed with n-hexane (10) and phenolic compounds were eluted with methanol. The methanolic extract was evaporated to dryness under reduced pressure $\left(40^{\circ} \mathrm{C}\right)$, redissolved in methanol $(4 \mathrm{~mL})$, and $20 \mu \mathrm{L}$ were analysed by HPLC.

\section{Extraction via Simplified Technique}

Each olive fruit sample (ca. $1.5 \mathrm{~g}$ ) was thoroughly mixed with methanol until complete extraction of the phenolic compounds (negative reaction to $\mathrm{NaOH}$ $20 \%$ ). The methanolic extract was filtered, evaporated to dryness under reduced pressure $\left(40^{\circ} \mathrm{C}\right)$, redissolved in methanol $(4 \mathrm{~mL})$, and $20 \mu \mathrm{L}$ were analysed by HPLC.

\section{HPLC Analysis of Phenolic Compounds}

Separation of phenolics was achieved with an analytical HPLC unit (Gilson), using a Spherisorb ODS2 $(25.0 \times 0.46 \mathrm{~cm} ; 5 \mu \mathrm{m}$, particle size $)$ column. The solvent system used was a gradient of water-formic acid (19:1) (A) and methanol (B): $0^{\prime}-5^{\circ} \%$ B, 3' $-15 \%$ B, $13^{\prime}-25 \%$ B, $25^{\prime}-30 \%$ B, $35^{\prime}-35 \%$ B, $39^{\prime}$ $-40 \%$ B, $42^{\prime}-45^{\circ} \%$ B, $45^{\prime}-45 \%$ B, $50^{\prime}-47^{\prime} \%$ B, $60^{\prime}-48 \%$ B, $64^{\prime}-50 \%$ B, $66^{\prime}$ $100 \% \mathrm{~B}$. The solvent flow rate used was $0.9 \mathrm{~mL} / \mathrm{min}$. Detection was achieved with a Gilson diode array detector (DAD), and chromatograms were recorded at 280 and $320 \mathrm{~nm}$. The data were processed on a Unipoint ${ }^{\mathrm{H}}$ system software (Gilson Medical Electronics, Villiers le Bel, France). The compounds in each sample were identified by comparing their retention times and UV-Vis spectra in the $200-400 \mathrm{~nm}$ range, with the library of spectra previously compiled by the 
authors. Peak purity was checked by means of the Gilson 160 SpectraViewer Software Contrast Facilities.

Phenolic compounds quantification was achieved by the absorbance recorded in the chromatograms relative to external standards. Once hydroxytyrosol and verbascoside were not commercially available, they were quantified as tyrosol and 5-O-caffeoylquinic acid, respectively. The other compounds were quantified as themselves.

\section{RESULTS AND DISCUSSION}

\section{Analytical Curves and Detection Limits}

Under the assay conditions described, a linear relationship (Table 1) between the concentration of tyrosol and oleuropein and the UV absorbance at $280 \mathrm{~nm}$ was obtained, as happened with 5-O-caffeoylquinic acid, luteolin-7-Oglucoside, rutin, apigenin-7-O-glucoside, quercetin 3-rhamnoside, and luteolin and the UV absorbance at $320 \mathrm{~nm}$. The correlation coefficient for the standard curves invariably exceeded 0.98 , for all phenolic compounds. The calibration curves (Table 1) were obtained by triplicate determinations of each of the calibration standards; the peak area values (arbitrary units) were plotted as average values. The relative percent average deviations of triplicates were less than $2 \%$, in all cases. The detection limit values were calculated as the

Table 1. Equations for Regression Lines and Correlation Coefficients, Concentration Range of Linearity and Detection Limits for Phenolic Compounds

\begin{tabular}{|c|c|c|c|c|}
\hline \multirow{2}{*}{$\begin{array}{l}\text { Phenolic Compounds } \\
\text { Tyrosol }\end{array}$} & \multicolumn{2}{|c|}{ Equation } & \multirow{2}{*}{$\begin{array}{c}\begin{array}{c}\text { Linearity } \\
(\mu \mathrm{g} / \mathrm{mL})\end{array} \\
120.0-960.0\end{array}$} & \multirow{2}{*}{$\begin{array}{c}\begin{array}{c}\text { Detection } \\
\text { Limit } \\
(\mu \mathrm{g} / \mathrm{mL})\end{array} \\
2.21\end{array}$} \\
\hline & $y^{\prime}=1.06 \times 10^{7} x$ & $\mathrm{r}=0.99418$ & & \\
\hline 5-O-Caffeoylquinic acid & $y=5.37 \times 10^{8} x$ & $\mathrm{r}=0.99835$ & $50.0-400.0$ & 0.04 \\
\hline Luteolin 7-O-glucoside & $y=3.41 \times 10^{7} x$ & $\mathrm{r}=0,99867$ & $120.0-960.0$ & 0.69 \\
\hline Oleuropein & $y^{\prime}=5,44 \times 10^{6} x$ & $\mathrm{r}=0.98588$ & $625.0-5000.0$ & 4.32 \\
\hline Rutin & $y=1.96 \times 10^{7} x$ & $\mathrm{r}=0.99856$ & $487.5-3900.0$ & 1.20 \\
\hline Apigenin 7-O-glucoside & $y=5.46 \times 10^{7} x$ & $\mathrm{r}=0.99850$ & $117.5-940.0$ & 0.43 \\
\hline Quercetin 3- $O$-rhamnoside & $y=3.48 \times 10^{7} x$ & $\mathrm{r}=0.99860$ & $75.0-600.0$ & 0.68 \\
\hline Luteolin & $y=5.36 \times 10^{7} x$ & $\mathrm{r}=0.99856$ & $47.5-380.0$ & 0.44 \\
\hline
\end{tabular}

$\mathrm{y}$-peak area at $320 \mathrm{~nm} ; \mathrm{y}^{\prime}$-peak area at $280 \mathrm{~nm} ; \mathrm{x}-\mu \mathrm{g}$ of phenolic compound; $\mathrm{r}$-correlation coefficient. 
concentration corresponding to three times the standard deviation of the background noise.

\section{Validation of the Method}

The phenolics from three Portuguese olive fruit cultivars were analysed by the proposed technique (Table 2 ), in order to validate this procedure and assess its application to the routine phenolic analysis of olive fruits. Due to the low recovery rate of oleuropein when the extraction via SPE column was used, the simplified technique was for its quantification in olive fruit cultivars.

With the extraction via the SPE column, the chromatograms (Figure 1) appeared somewhat cleaner than those obtained with the extraction via the simplified technique and, as a general rule, the amount of each phenolic compound extracted was higher, except for oleuropein (Figure 2). The retention times (RT) obtained for phenolic compounds were: RT $8 \mathrm{~min} 58 \mathrm{sec}$ for hydroxytyrosol; RT $16 \mathrm{~min} 26 \mathrm{sec}$ for 5 - $O$-caffeoylquinic acid; RT $32 \mathrm{~min} 12 \mathrm{sec}$ for verbascoside; RT $41 \mathrm{~min} 8 \mathrm{sec}$ for luteoline-7-O-glucoside; RT $42 \mathrm{~min} 15 \mathrm{sec}$ for oleuropein; RT $43 \mathrm{~min} 37 \mathrm{sec}$ for rutin; RT $46 \mathrm{~min} 15 \mathrm{sec}$ for apigenin-7- $O$ glucoside; RT $47 \mathrm{~min} 31 \mathrm{sec}$ for quercetin 3-rhamnoside and RT $61 \mathrm{~min} 58 \mathrm{sec}$ for luteolin.

The extract obtained from Cobrançosa olive fruit has the same qualitative composition as that obtained from Madural olive fruit. Verdeal olive fruit exhibited a similar phenolic composition, but verbascoside was not present.

Table 2. Phenolic Compounds Composition of Olive Fruit Samples $(\mathrm{mg} / \mathrm{Kg})^{\mathrm{a}}$ (Quantification by External Standard Techniques)

\begin{tabular}{llll}
\hline & \multicolumn{3}{c}{ Cultivars } \\
\cline { 2 - 4 } Phenolic Compounds & \multicolumn{1}{c}{ Cobrançosa } & \multicolumn{1}{c}{ Madural } & \multicolumn{1}{c}{ Verdeal } \\
\hline Hydroxytyrosol & $1439.8(28.42)$ & $44684(144.50)$ & $558.5(27.69)$ \\
5-O-Caffeoylquinic acid & $1.9(0.03)$ & $4.4(0.14)$ & $1.1(0.02)$ \\
Verbascoside & $44.5(0.85)$ & $47.1(0.91)$ & - \\
Luteolin 7-O-glucoside & $218.3(3.98)$ & $840.8(7.37)$ & $36.9(0.05)$ \\
Oleuropein* & $2570.6(59.96)$ & $17994.7(458.08)$ & $36837.3(143.59)$ \\
Rutin & $505.4(4.08)$ & $959.1(15.51)$ & $158.3(1.92)$ \\
Apigenin 7-O-glucoside & $38.5(0.86)$ & $134.7(3.42)$ & $15.1(0.10)$ \\
Quercetin 3-O-rhamnoside & $60.1(1.26)$ & $113.7(5.98)$ & $19.5(0.18)$ \\
Luteolin & $26.0(0.51)$ & $53.5(1.43)$ & $2.2(0.46)$ \\
\hline
\end{tabular}

${ }^{\mathrm{a}}$ Values are expressed as mean (standard deviation) of three determinations.

*Oleuropein was determined by the simplified technique. 

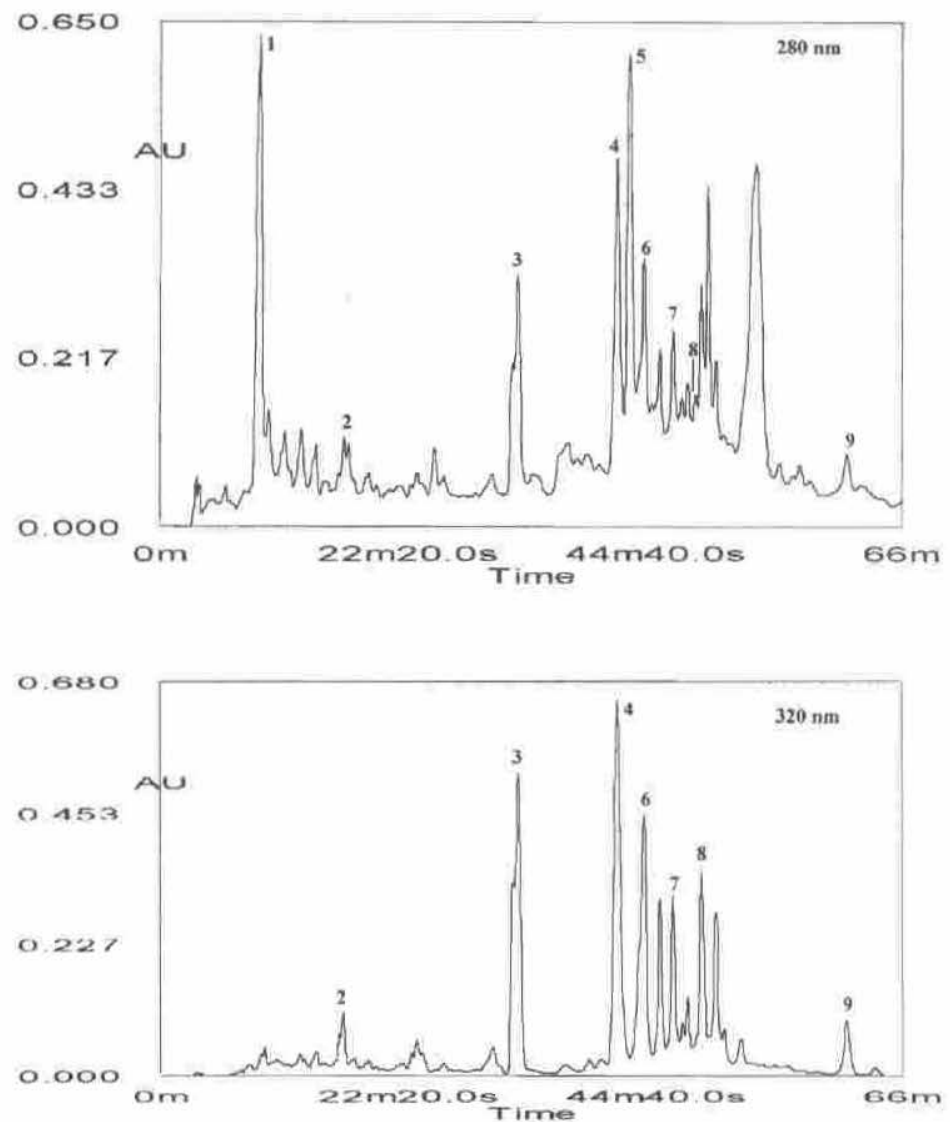

Figure 1. HPLC profile of olive fruit sample (Madural cultivar) obtained by SPE column. (1) hydroxytyrosol; (2) 5-O-caffeoylquinic; (3) verbascoside; (4) luteolin 7-Oglucoside; (5) oleuropein; (6) rutin; (7) apigenin 7-O-glucoside; (8) quercetin 3-Orhamnoside; (9) luteolin.

The precision of the analytical method was evaluated by measuring the peak chromatographic area of phenolic compounds six times on the same sample. The analytical method is precise, once the coefficients of variation of phenolics were between 0.81 and $2.22 \%(n=6)$ (Table 3 ).

In order to study the recovery of the procedure, a powdered olive fruit sample was added to known quantities of luteoline-7-O-glucoside, oleuropein, rutin, apigenin-7-O-glucoside, quercetin 3-rhamnoside, and luteolin (Table 4). The sample was analysed in triplicate before and after the additions. Recovery 


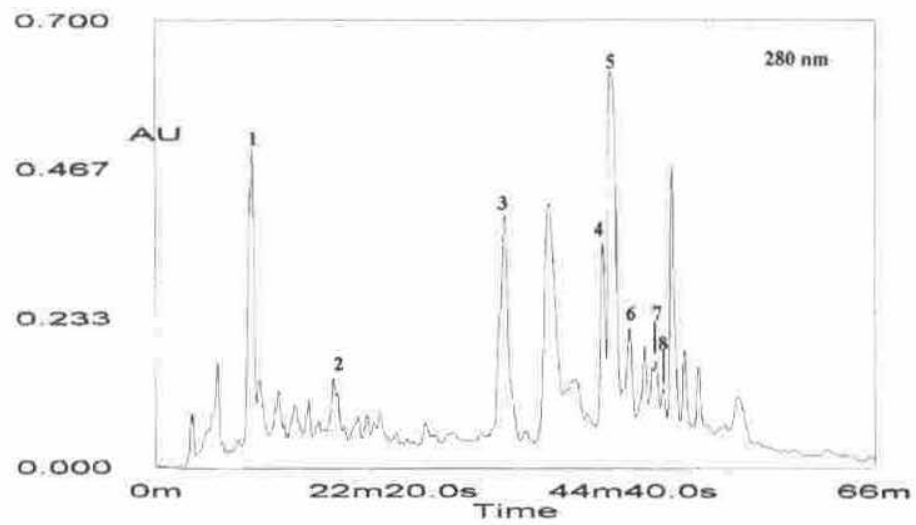

Figure 2. HPLC profile of olive fruit sample (Madural cultivar) obtained by extraction via simplified technique. (1) hydroxytyrosol; (2) 5-O-caffeoylquinic; (3) verbascoside; (4) luteolin 7-O-glucoside; (5) oleuropein; (6) rutin; (7) apigenin 7-O-glucoside; (8) quercetin 3-O-rhamnoside; (9) luteolin.

values were between 87.3 and $94.9 \%$ for luteoline-7-O-glucoside, 90.2 and $96.9 \%$ for oleuropein, 78.3 and $88.3 \%$ for rutin, 82.0 and $97.1 \%$ for apigenin-7$O$-glucoside, 77.9 and $85.2 \%$ for quercetin 3-rhamnoside, and 88.5 and $100.6 \%$ for luteolin. This procedure demonstrated the effectiveness of the extraction and the accuracy of the proposed method.

Table 3. Evaluation of the Analytical Method Precision $(n=6)$ (Quantification by External Standard Techniques)

\begin{tabular}{lcc}
\hline Phenolic Compounds & $\mathrm{SD}(\mathrm{mg} / \mathrm{Kg})$ & $\mathrm{CV}(\%)$ \\
\hline Hydroxytyrosol & 28.42 & 1.97 \\
5 -O-caffeoylquinic acid & 0.03 & 1.81 \\
Verbascoside & 0.85 & 1.90 \\
Luteolin-7-O-glucoside & 3.98 & 1.82 \\
Oleuropein* & 32.67 & 1.65 \\
Rutin & 4.08 & 0.81 \\
Apigenin-7-O-glucoside & 0.86 & 2.22 \\
Quercetin-3-O-rhamnoside & 1.26 & 2.09 \\
Luteolin & 0.51 & 1.98 \\
\hline
\end{tabular}

$\mathrm{SD}$-standard deviation; $\mathrm{CV}$ - coefficient of variation.

*Oleuropein was determined by the simplified technique. 
Table 4. Recoveries of Phenolic Compounds from an Olive Fruit Sample (Quantification by External Standard Techniques)

\begin{tabular}{|c|c|c|c|c|c|c|}
\hline Phenolic Compounds & Present $(\mathrm{mg} / \mathrm{Kg})$ & Added $(\mathrm{mg} / \mathrm{Kg})$ & Found $(\mathrm{mg} / \mathrm{Kg})^{\mathrm{a}}$ & $\mathrm{SD}(\mathrm{mg} / \mathrm{Kg})$ & CV $(\%)$ & Recovery (\%) \\
\hline \multirow[t]{3}{*}{ Luteolin-7-O-glucoside } & 840.8 & 800.0 & 1511.4 & 29.73 & 1.97 & 92.1 \\
\hline & & 1400.0 & 1956.2 & 62.64 & 3.20 & 87.3 \\
\hline & & 2384.1 & 3059.3 & 24.75 & 0.81 & 94.9 \\
\hline \multirow[t]{3}{*}{ Oleuropein* } & 17994.7 & 2666.7 & 18630.4 & 398.62 & 2.14 & 90.2 \\
\hline & & 4000.0 & 21317.3 & 1912.70 & 8.97 & 96.9 \\
\hline & & 5333.3 & 22520.5 & 2851.96 & 12.66 & 96.5 \\
\hline \multirow[t]{3}{*}{ Rutin } & 959.1 & 200.0 & 907.5 & 16.00 & 1.76 & 78.3 \\
\hline & & 397.4 & 1198.4 & 24.89 & 2.08 & 88.3 \\
\hline & & 600.0 & 1228.9 & 44.58 & 3.63 & 78.8 \\
\hline \multirow[t]{3}{*}{ Apigenin-7-O-glucoside } & 134.7 & 331.1 & 438.8 & 9.19 & 2.09 & 94.2 \\
\hline & & 596.0 & 599.4 & 3.74 & 0.62 & 82.0 \\
\hline & & 1000.0 & 1101.7 & 14.25 & 1.29 & 97.1 \\
\hline \multirow[t]{3}{*}{ Quercetin-3-O-rhamnoside } & 113.7 & 132.4 & 191.6 & 11.69 & 6.10 & 77.9 \\
\hline & & 198.7 & 266.2 & 16.92 & 6.36 & 85.2 \\
\hline & & 335.6 & 372.5 & 5.86 & 1.57 & 82.9 \\
\hline \multirow[t]{3}{*}{ Luteolin } & 53.5 & 132.5 & 183.9 & 4.36 & 2.37 & 98.9 \\
\hline & & 264.9 & 320.4 & 9.35 & 2.92 & 100.6 \\
\hline & & 400.0 & 401.5 & 0.15 & 0.04 & 88.5 \\
\hline
\end{tabular}

${ }^{a}$ Mean value found for three assays for each studied concentration; SD-standard deviation; CV-coefficient of variation.

*Oleuropein was determined by the simplified technique. 
In conclusion, the proposed procedure is sensitive, reproducible, and accurate; suitable for routine analysis of phenolics in olive fruits, allowing the discrimination of different cultivars of Portuguese olive fruits from Trás-osMontes.

\section{ACKNOWLEDGMENT}

Branca M. Silva is grateful to Fundação para a Ciência e a Tecnologia for a grant (PRAXIS XXI/BD/21339/99).

\section{REFERENCES}

1. Romani, A.; Mulinacci, N.; Pinelli, P.; Vincieri, F.F.; Cimato, A. Polyphenolic Content in Five Tuscany Cultivars of Olea europaea L. J. Agric. Food Chem. 1999, 47, 964967.

2. Andrade, P.B.; Leitão, R.; Seabra, R.M.; Oliveira, M.B.; Ferreira, M.A. Development of an HPLC/Diode-Array Detector Method for Simultaneous Determination of Seven Hydroxy-Cinnamic Acids in Green Coffee. J. Liq. Chrom. \& Rel. Technol. 1997, 20 (13), 2023-2030.

3. Andrade, P.B.; Ferreres, F.; Amaral, M.T. Analysis of Honey Phenolic Acids by HPLC, its Application to Honey Botanical Characterization. J. Liq. Chrom. \& Rel. Technol. 1997, 20 (14), 2281-2288.

4. Andrade, P.B.; Carvalho, A.R.F.; Seabra, R.M..; Ferreira, M.A. A Previous Study of Phenolic Profiles of Quince, Pear, and Apple by HPLC Diode Array Detection for the Evaluation of Quince Puree Genuineness. J. Agric. Food Chem. 1998, 46, 968-972.

5. Soler-Rivas, C.; Espin, J.C.; Wichers, H. Oleuropein and Related Compounds. J. Sci. Food Agric. 2000, 80, 1013-1023.

6. Capasso, R.; Evidente, A.; Scognamiglio, F.A Simple Thin Layer Chromatographic Method to Detect the Main Polyphenols Occurring in Olive Oil Vegetation Waters. Phytochem Anal. 1992, 3, 270-275.

7. Ficarra, P.; Ficarra, R.; de Pasquale, A.; Monforte, M.T.; Calabro M.L. HPLC Analysis of Oleuropein and Some Flavonoids in Leaf and Bud of Olea Europaea L. Farmaco 1991, 46, 803-815.

8. De Laurentis, N.; Crescenzo, G.; Lai, O.R.; Milillo, M.A. Investigation on the Extraction and Concentration of Oleuropein and Flavonoids in Olea Europaea L. Based Products. Pharm. Pharmacol. Lett. 1997, 7, 27-30.

9. Baracco, A.; Bergin, G.; Gnocco, E.; Legorati, M.; Sedocco, S.; Catinella, S.; Fravretto, D.; Traldi, P. A Comparison of the Combination of Fast-Atom Bombardment with Tandem Mass Spectrometry and Gas Chromatography 
with Mass Spectrometry in the Analysis of a Mixture of Kaempferol, Kaempferide, Luteolin and Oleuropein. Rapid Commun. Mass Spectrom. $1995,9,427-436$.

10. Ryan, D.; Robards, K. Phenolic Compounds in Olives. Analyst 1998, 123, $31-44$.

Received June 30, 2001

Accepted July 21, 2001

Manuscript 5611 
Copyright $@ 2003$ EBSCO Publishing 